\title{
Cost Minimization Energy Control Including Battery Aging for Multi-Source EV Charging Station
}

\author{
Umberto Abronzini ${ }^{1}\left(\mathbb{D}\right.$, Ciro Attaianese ${ }^{1}\left(\mathbb{D}\right.$, Matilde D’Arpino ${ }^{2}{ }^{\circledR}$, Mauro Di Monaco ${ }^{1, *}$ \\ and Giuseppe Tomasso ${ }^{1}$ (D) \\ 1 Department of Electrical and Information Engineering “M. Scarano”, University of Cassino and \\ Southern Lazio, 03043 Cassino, Italy; u.abronzini@unicas.it (U.A.); attaianese@unicas.it (C.A.); \\ tomasso@unicas.it (G.T.) \\ 2 Center for Automotive Research, The Ohio State University, Columbus, OH 43210, USA; darpino.2@osu.edu \\ * Correspondence: m.dimonaco@unicas.it
}

Received: 3 November 2018; Accepted: 27 December 2018; Published: 1 January 2019

\begin{abstract}
A Multi-Source Electric Vehicle Charging Station (MS-EVCS) is a local entity that combines the grid energy with Distributed Energy Resources (DERs) with the aim of reducing the grid impact due to electric vehicles (EVs) charging events. The integration of stationary and in-vehicle Energy Storage Systems (ESSs) in MS-EVCSs has gained increasing interest thanks to the possibility of storing energy at off-peak hours to be made available at peak-hours. However, the ESS technology and the vehicle-to-grid (V2G) concept show several issues due to cost, battery life cycle, reliability, and management. The design of the MS-EVCS energy management system is of primary importance to guarantee the optimal usage of the available resources and to enhance the system benefits. This study presents a novel energy management strategy for Real-Time (RT) control of MS-EVCS considering DERs, stationary ESS, and V2G. The proposed energy management control allows defining the MS-EVCS control policy solving several cascaded-problems with the aim of achieving the minimum operating cost when the battery degradation and the stochastic nature of the sources are considered. The key feature of the proposed methodology is the lower computational effort with respect to traditional optimal control methodologies while achieving the same optimal solution.
\end{abstract}

Keywords: EV charging stations; battery aging; distributed energy sources (DESs); optimal power flow management

\section{Introduction}

Nowadays, Energy Storage Systems (ESSs) are a key technology for efficiency improvement in several applications, such as industrial systems, grid infrastructures, Distributed Energy Sources (DESs), and Electric Vehicles (EVs) charging infrastructures. With reference to the growing penetration of EVs, new technology challenges have to be faced in terms of EV charging management to create a sustainable mobility infrastructure for users, electric utilities, as well as local administrations [1-3]. The energy requirement for EV charging can strongly affect the electric grid, degrading the power quality and system stability, while increasing the power losses. DC fast charging further exacerbates these problems. In recent years, the industrial and academic communities have been driving the research on new smart charging concepts [4-6] with the aim of minimizing the reinforcement of the grid infrastructure needed to meet the power demand of EVs. The integration of stationary ESSs and DESs in the EV Charging Stations (EVCSs), also known as Multi-Source EVCSs (MS-EVCSs), can potentially minimize the grid impact and improve the "well-to-wheel" efficiency of EVs. MS-EVCS approaches can achieve valley filling and peak shaving of the grid power request, reduce the grid tie capacity, enhance the fast-charge capabilities, increase system stability, as well as providing ancillary 
services to the grid. In this scenario, aggregated power from the EVs' on-board batteries may be used to support local loads, grid, or other vehicles, providing the well-known Vehicle-to-Grid (V2G) service. Proper incentives and policy are necessary to regulate and coordinate the use of the in-vehicle energy at the system level through third-party aggregators or parking lot operators [7]. It is clear that there are several challenges to address in this scenario. The coordination between the available sources represents a degree of freedom for the MS-EVCS, but at the same time it increases the complexity of system sizing and Energy Management Control (EMC). The EMC can be designed to minimize the grid energy provision, the operative cost, and/or the grid impact [8-10]; while the degradation of the stationary ESSs due to repeated charge/discharge cycles cannot be neglected in the control design. In [11-15] non-linear models for ESS capacity fade are presented to describe calendar-life and life cycle aging using electrochemical, heuristic, or experimental approach. In literature, several optimization techniques have been exploited $[3,5,16]$ to solve non-linear optimal control problems in the field of MS-EVCSs, based on Dynamic Programming (DP), Direct and Indirect Methods, and Model Predictive Control (MPC). These techniques achieve very accurate solution, but require very high computational power, which is usually incompatible with real-time implementation.

In this paper, a novel EMC based on the minimization of the operating cost of the MS-EVCS is proposed including the degradation costs of the ESSs and technical and economic constraints. The proposed Multi-Layer Dynamic EMC (ML-DEMC) is based on a heuristic approach that allows splitting the optimization problem into several cascaded sub-problems (layers) on the basis of the definition of a proper set of source-provision priorities, which are assigned in function of the given mission of the system. In this paper, the energy of the auxiliary sources (DES, V2G, and ESS) has the primary aim of supporting the EV charging process and not the grid. Nevertheless, the flexibility of the proposed algorithm easily allows for the inclusion of additional operating modes through the definition of new priority levels. In the considered scenario, the Stationary ESS (S-ESS) can store energy during DES production surplus, low-cost grid electricity, and V2G service periods. An external V2G EMC is developed to emulate the aggregator functionalities considering the V2G constraints. A stochastic approach, based on Probability Density Functions (PdFs), enables the prediction of a statistic control policy of the MS-EVCS. A day-ahead analysis is used to predict the optimal initial state of charge (SoC) of the S-ESS that enables the optimal use of the ESS. Also, the efficiency of power conversion units is taken into account to define the optimal operating point. A DP solver [17] is used in this paper to verify the performance of the proposed ML-DEMC in terms of solution optimality and computational burden. This paper is organized as following. In Section 2, the mathematical model of the MS-EVCS is presented within a control-oriented ESS degradation model and V2G. The optimization problem is defined in Section 2.3, while Section 3 reports the proposed ML-DEMC. In Section 4, the implementation of the MS-EVCS mathematical model and the control technique are reported together with numerical results and discussion. Finally, Section 5 provides conclusions.

\section{System Model}

The considered MS-EVCS consists of a Power Conversion System (PCS) capable of supplying the EV charging load by different energy sources: grid, Photovoltaic Field (PV), V2G, and a S-ESS, as depicted in Figure 1a. The power is summed on a common DC-link with the aim of optimizing the conversion efficiency $[4,5]$. The connected EVs are divided into two groups distinguished by the owners' preference regarding V2G participation. EVSEs are used to implement the interface between the PCS and the EVs, taking into account different power levels, charging methodologies (AC, DC), and bidirectional functionalities. 


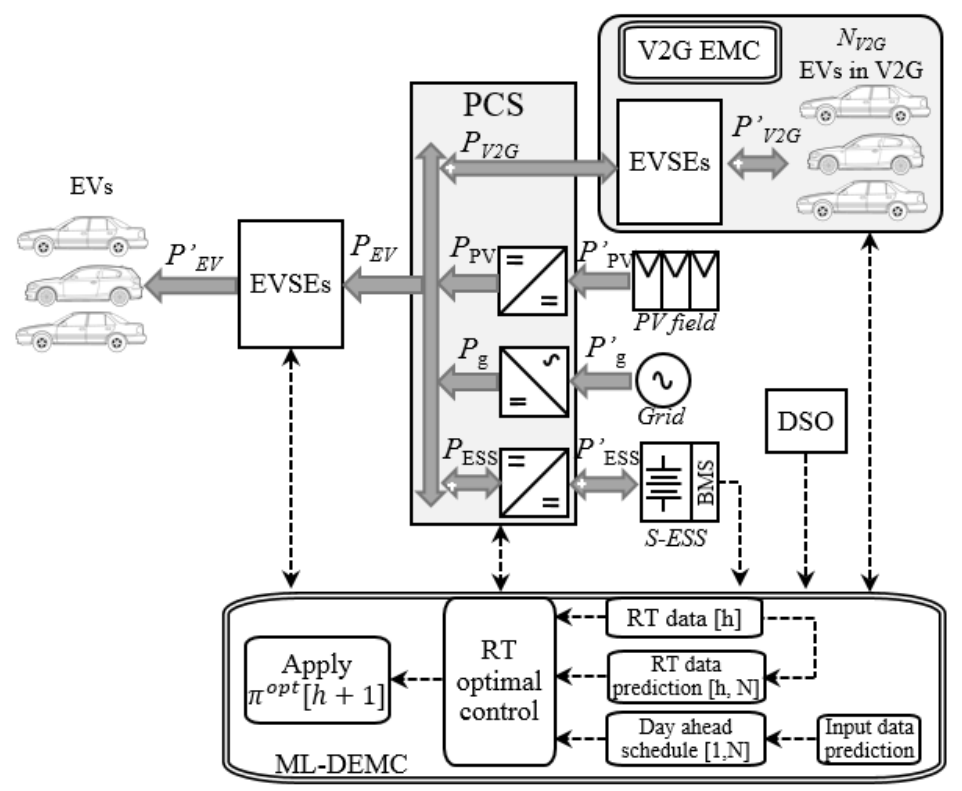

(a)

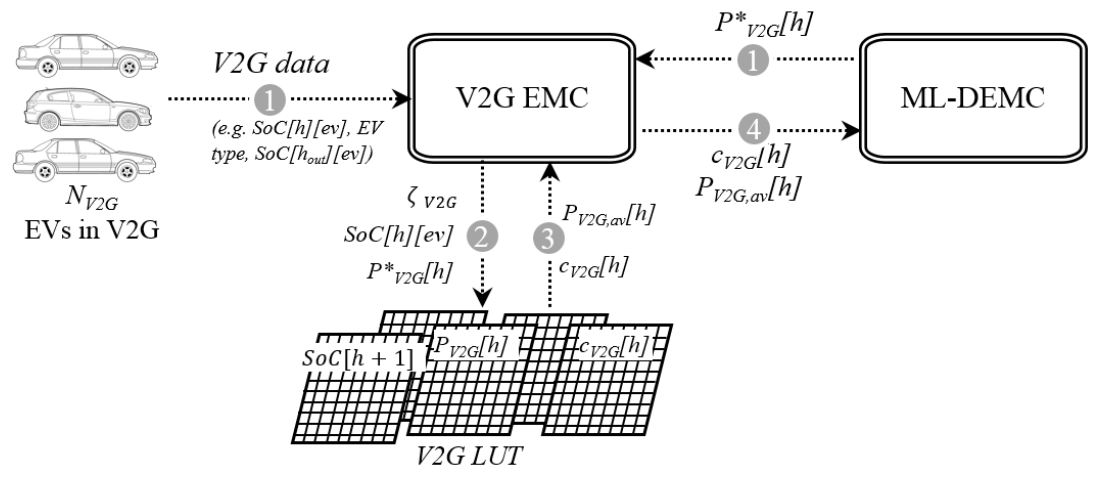

(b)

Figure 1. (a) Structure of the Multi-source EV charging station. (b) Communication protocol between V2G EMC and ML-DEMC.

The power balance at the DC-link of the MS-EVCS can be expressed by:

$$
P_{\mathrm{EV}}=P_{\mathrm{g}}+P_{\mathrm{PV}}+P_{\mathrm{S}-\mathrm{ESS}}+P_{\mathrm{V} 2 \mathrm{G}}
$$

where $P_{\mathrm{EV}}, P_{\mathrm{g}}, P_{\mathrm{PV}}, P_{\mathrm{S}-\mathrm{ESS}}$, and $P_{\mathrm{V} 2 \mathrm{G}}$ respectively represent the power provided/drawn at the DC-link by EVs, grid, PV field, S-ESS, and V2G. The direction of the power flow for each component connected to DC-link and its reference are represented in Figure 1a. The power of $\mathrm{i}$-th source, $P_{\mathrm{i}}^{\prime}$ with $\mathrm{i}=\mathrm{g}$, $\mathrm{PV}, \mathrm{S}$-ESS, and V2G, is evaluated considering the power-dependent efficiency values, $\eta_{\mathrm{i}}$, of its power conversion unit:

$$
P_{\mathrm{i}}^{\prime}=\frac{P_{\mathrm{i}}}{\eta_{\mathrm{i}}}
$$

In the same manner, the power to load, $P_{\mathrm{EV}}^{\prime}$, is yielded by:

$$
P_{\mathrm{EV}}^{\prime}=\eta_{\mathrm{EV}} P_{\mathrm{EV}}
$$


Moreover, every source has upper and lower power limits:

$$
P_{\mathrm{i}}^{\min } \leq P_{\mathrm{i}}^{\prime} \leq P_{\mathrm{i}}^{\max }
$$

The minimum and maximum boundary values $\left(P_{\mathrm{i}}^{\min }, P_{\mathrm{i}}^{\max }\right)$ are function of the system operating conditions and source characteristics. A Maximum Power Point Tracking (MPPT) algorithm determines the maximum power available from the PV field [18]. The ESS and V2G models are reported in Sections 2.1 and 2.2, respectively.

An operating cost for every source is taken into account in order to define the cost objective function of the energy management control (Section 2.3). In detail, the MS-EVCS operating $\operatorname{cost} c_{\pi}$ is defined as,

$$
c_{\pi}=c_{\mathrm{g}}+c_{\mathrm{PV}}+c_{\mathrm{deg}}+c_{\mathrm{V} 2 \mathrm{G}}
$$

where $c_{\mathrm{g}}$ is the real-time electricity cost, obtained by the Distribution System Operator (DSO); $c_{\mathrm{PV}}$ is the operating cost of the PV system; $c_{\mathrm{deg}}$ and $c_{\mathrm{V} 2 \mathrm{G}}$ are the S-ESS and V2G costs (Sections 2.1 and 2.2).

\subsection{Energy Storage System}

In grid application, ESS can be implemented with a single technology (e.g., battery, supercapacitors, fly-wheel) as well as with hybrid solutions with the aim to improve the dynamic response and efficiency of the MS-EVCS [19]. For simplicity, a battery-based ESS is considered in this paper. The state-of-charge $(\mathrm{SoC})$ represents the energy available at the following time instant $(h+1)$ when the ESS is subject to a power flow equal to $P_{\mathrm{ESS}}^{\prime}$, as shown in the following equation:

$$
S o C[h+1]=S o C[h]+ \begin{cases}-\frac{\eta_{\mathrm{C}} P_{\mathrm{ESS}}^{\prime}[h]}{E_{\mathrm{ESS}}} T_{\mathrm{S}} & \text { if }\left(P_{\mathrm{ESS}}^{\prime}[h]<0\right) \\ -\frac{P_{\mathrm{ESS}}^{\prime}[h]}{\eta_{d} E_{\mathrm{ESS}}} T_{\mathrm{S}} & \text { if }\left(P_{\mathrm{ESS}}^{\prime}[h]>0\right)\end{cases}
$$

where $S o C[h]$ is the initial $S_{0} C, E_{\mathrm{ESS}}$ is the energy capacity of ESS, $\eta_{\mathrm{c}}$ and $\eta_{\mathrm{d}}$ are the charge and discharge energy efficiency, respectively. $T_{\mathrm{S}}$ is the time interval between two evaluations of the SoC. The unitary complement of the $S o C$ is defined as depth-of-discharge $(D o D=1-S o C)$. The ESS power limits in charge and discharge $\left(P_{\mathrm{ESS}, \mathrm{d}}^{\max }, P_{\mathrm{ESS}, \mathrm{c}}^{\max }\right)$ are usually evaluated by standard Hybrid Pulse Power Characterization (HPPC) test and considering the thermal limitations of the battery pack [20].

As is well known, controlling the $S o C$ and power flow within the maximum and minimum values guarantees a safe operation of the ESS and maximizes its lifetime and performance. However, over time the capacity of an ESS is influenced by the operative conditions (c-current rates, temperature, DoD, SoC, end-of-charge voltage, etc.) [11-13]. The control strategy has to consider the degradation phenomena to avoid to speed up the ESS fade. Nevertheless, some of the degradation factors can be neglected, depending on the application $[11,13,15]$, in order to avoid increasing the control complexity due to the increment of the model non-linearities. As example, in stationary application (e.g., MS-EVCS) the charge and discharge rates of ESSs can be limited in order to reduce their impact on the battery aging, and to obtain negligible temperature variation. Under these hypothesis, the $D o D$ is here considered as the single factor that influences the degradation process.

A control-oriented aging model has been included in the proposed EMC to evaluate the lost of lifetime of the ESS, at each use, based on $L(D o D)$ characteristics provided by the battery manufacturer or experimental data, which predicts the achievable life cycles (charge/discharge cycles) as a function of operating $D o D$. Batteries subject to deeper $D o D$ experience a lower number of life cycles and a higher fade of the available capacity early in life. The relationship between cycle life and $D o D$ depends on the battery chemistry and operating conditions, [11]. Starting from the function $L(D o D)$ 
and the capital cost of the ESSs $c_{E S S}[11,12]$, the degradation cost $\left(c_{\mathrm{deg}}\right)$ due to the battery discharge from $D o D_{1}$ to $D o D_{2}$ (where $D o D_{2}>D o D_{1}$ ) can be carried out with the following equation:

$$
c_{\mathrm{deg}}[h]=\left(\frac{1}{L\left(D o D_{2}\right)}-\frac{1}{L\left(D o D_{1}\right)}\right) c_{\mathrm{ESS}}
$$

\subsection{Vehicle to Grid (V2G)}

A multitude of business models have been proposed in literature with the aim to quantify the benefit of V2G mode including also the aging of the vehicle battery packs $[7,13,21,22]$. In this analysis, the EVs participation in the V2G mode is managed by an external agent (V2G EMC) that dynamically provides aggregated power availability to the charging station, Figure $1 \mathrm{~b}$. In the considered scenario, the vehicle owner communicates to the V2G EMC the time at which the EV should be charged, the desired charge level, and its availability for V2G participation. For the participation in this service, the $e v$-th vehicle is remunerated with $\rho_{V 2 G}$ :

$$
\rho_{V 2 G}[e v]=\lambda_{\mathrm{V} 2 \mathrm{G}}[e v]+c_{\mathrm{degV} 2 \mathrm{G}}[e v]
$$

where $\lambda_{\mathrm{V} 2 \mathrm{G}}$ represents the V2G profit and $c_{\mathrm{degV} 2 \mathrm{G}}$ is the EV-ESS degradation cost. The following assumptions are here considered:

- $\quad \rho_{V 2 G}$ is not a function of the grid energy cost;

- $\quad$ the remuneration $\lambda_{\mathrm{V} 2 \mathrm{G}}$ of each $\mathrm{EV}$ is proportional to the energy provided in V2G mode;

- $\quad c_{\mathrm{degV} 2 \mathrm{G}}$ is function of $D o D$ and battery capital cost of the $e v$-th vehicle (Equation (7)).

At every sampling interval, the V2G EMC tentatively provides to the MS-EVCS a power availability, that may allow for a cost reduction of the charging station energy provision. A fleet of $N_{\mathrm{V} 2 \mathrm{G}}$ vehicles may participate in the V2G mode, thus the V2G EMC has to evaluate at every instant which combination of vehicles (within the available ones) allows minimizing the V2G service cost guaranteeing, if possible, the MS-EVCS power request $P_{\mathrm{V} 2 \mathrm{G}}^{*}$. Thus, considering that $c_{V 2 G}=\sum_{e v=1}^{N_{V 2 G}} \rho_{V 2 G}[e v]$ is highly influenced by the $S o C$ level of the EVs and the capital cost of the battery packs, the V2G EMC will find the best combination of EV power that allows achieving the required power at the minimum fleet degradation cost. Under the hypothesis that the V2G EMC has knowledge of the parameters of the $N_{\mathrm{V} 2 \mathrm{G}}$ vehicles of the fleet (power limits, SoC limits, efficiency maps, time availability in $\mathrm{V} 2 \mathrm{G}$ mode, and actual $\mathrm{SoC}$ ), a proper optimization problem can be defined and off-line solved considering all the possible combinations of available EVs, $S o C[e v]$ patterns, and $P_{\mathrm{V} 2 \mathrm{G}}^{*}$. Therefore, if $N_{\mathrm{V} 2 \mathrm{G}}$ is the number of vehicles in the fleet, $\zeta_{\mathrm{V} 2 \mathrm{G}}$ combinations can be identified:

$$
\zeta_{\mathrm{V} 2 \mathrm{G}}=\sum_{e v=1}^{N_{\mathrm{V} 2 \mathrm{G}}} \frac{N_{\mathrm{V} 2 \mathrm{G}} !}{e v !\left(N_{\mathrm{V} 2 \mathrm{G}}-e v\right) !}
$$

As example if $N_{\mathrm{V} 2 \mathrm{G}}=3$, the algorithm analyzes the condition in which only one of the three EVs is available ( 3 combinations), two EVs are available ( 3 combinations), all three EVs are available ( 1 combination). Thus, $\zeta_{\mathrm{V} 2 \mathrm{G}}=7$ and all the repetitions are avoided. A grid of $\mathrm{SoC}[e v]$ and $P_{\mathrm{V} 2 \mathrm{G}}^{*}$ is built considering the technology limits of the V2G ESS and the power limit of the fleet, respectively. For all of these system combinations (number and topology, vehicle available, SoC pattern, and power request), an optimization problem is formulated and solved with a DP algorithm [17] to find the optimal $P_{\mathrm{V} 2 \mathrm{G}}[h][e v]$ pattern that minimizes the cost $c_{V 2 G}$. The results are stored in static look-up tables in such a way that the V2G EMC can rapidly provide the cost $c_{V 2 G}$ and power information $P_{\mathrm{V} 2 \mathrm{G}, \mathrm{av}}[h]=\sum_{e v=1}^{N_{\mathrm{V} 2 \mathrm{G}}} P_{\mathrm{V} 2 \mathrm{G}}[h][e v]$ to the ML-DEMC considering the actual state of the fleet. Multi-dimensional interpolations are used to evaluate the operative points out of the grids. Finally, the V2G EMC provides a dynamic power request to the MS-EVCS to recharge the EVs in V2G mode and ensure the $S o C$ required by the owner. The cost of this energy will be considered in the MS-EVCS 
cost balance as $c_{r}$, as discussed in Section 3. The communication protocol between the V2G EMC and the ML-DEMC is represented in Figure 1b.

\subsection{Problem Statement}

The time-variant model of the MS-EVCS system can be synthesized at the $h$-th sampling time by:

$$
x_{\mathrm{j}}[h+1]=F_{\mathrm{j}, h}\left(x_{\mathrm{j}}[h], u_{\mathrm{k}}[h]\right)
$$

where $x_{\mathrm{j}}$ is a state variable representing the SoC of the j-th ESS, $u_{\mathrm{k}}$ is a input signal representing the power of the k-th source, with $\mathrm{k}=\mathrm{PV}, \mathrm{ESS}, \mathrm{V} 2 \mathrm{G} . F_{\mathrm{j}, h}$ represents the time-variant model of the system. A control policy $\pi[h]$ can be defined based on the three independent power references:

$$
\pi[h]=\left\{P_{\mathrm{PV}}^{*}[h], P_{\mathrm{ESS}}^{*}[h], P_{\mathrm{V} 2 \mathrm{G}}^{*}[h]\right\}
$$

while $P_{\mathrm{g}}^{\prime}[h]$ is used to balance the power to DC-link of the MS-EVCS under the load balance constraint in Equation (1). The proposed EMC strategy for MS-EVCS carries out the optimal control policy $\pi^{\text {opt }}$ that allows minimizing the operating cost of the charging infrastructure, shown in Figure 1a, over a time horizon. The cost function $C_{\pi}$ is expressed as the sum of the $h$-th operating $\operatorname{cost} c_{\pi}[h]$ (defined in Equation (5)) over the control horizon ( $N$ sampling intervals). The optimization problem is formulated as following:

$$
\min C_{\pi}=\sum_{h=1}^{N} c_{\pi}[h]
$$

subject to:

$$
\begin{aligned}
& x_{\mathrm{j}}[1]=x_{\mathrm{j}}[N] \quad \mathrm{j}=\text { S-ESS } \\
& x_{\mathrm{j}} \in \mathcal{X}_{\mathrm{j}} \& \pi \in \Pi
\end{aligned}
$$

model and constraints reported in Section 2

$\mathcal{X}_{\mathrm{j}}$ and $\Pi$ are the boundary constraints of the states and control policy (Section 2). The initial and final states are defined as follows:

$$
\left\{\begin{aligned}
x_{\mathrm{j}}[1] & =x_{\mathrm{in}, \mathrm{j}} \\
x_{\mathrm{j}}[N] & =x_{\mathrm{fin}, \mathrm{j}}
\end{aligned}\right.
$$

At every sampling time the ML-DEMC may require a reference power from the V2G EMC $\left(P_{\mathrm{V} 2 \mathrm{G}}^{*}\right)$, thus the V2G EMC provides information about the real-time available power $\left(P_{\mathrm{V} 2 \mathrm{G}, \mathrm{av}}\right)$ and the related $\operatorname{cost}\left(c_{V 2 G}\right)$. The ML-DEMC evaluates the economical convenience of using the V2G energy considering that an additional cost $\left(c_{r}\right)$ has to be taken into account to replace the V2G energy within the owner constraints (time, $\mathrm{SoC}$ ), considering the V2G model reported in Section 2.2.

\section{Multi-Layer Dynamic Energy Management Control}

The proposed ML-DEMC is a numerical framework for solving the unit-commitment problem of a MS-EVCS. With reference to Figure 1a, the mission of the ML-DEMC is the minimization of operating cost over the control horizon securing the load demand and the system constraints. A rule-based approach is proposed here that allows decomposing the problem formulated in Equation (12) into several cascaded sub-problems (referenced as called layers). Each layer optimizes the use of one or more sources of the MS-EVCS, as described in Section 3.2. A stochastic approach has been considered for the evaluation of the control policy under system uncertainty [22] by means of a Monte Carlo method. PdFs are defined for the PV energy production, EV charging load profile, grid energy price, and V2G availability [3]. The probabilistic control policy is evaluated solving the energy management problem for $N_{\mathrm{PdF}}$ deterministic scenarios. At every $h$-th sampling interval the ML-DEMC determines the optimal control policy $\pi^{\text {opt }}$ through the time horizon considering system uncertainty. However, only the first element of the control policy array $\pi^{\mathrm{opt}}[h+1]$ is applied. In the following control period, 
ML-DEMC adapts the control policy of MS-EVCS on the basis of possible variations between the forecast analysis and the actual working conditions, Figure 1a.

\subsection{Priority Level Definition}

The layers are defined using a ruled-based approach that sorts the MS-EVCS operating modes considering the increased operating costs. These layers are then addressed with a priority level that represents the order in which every sub-problem is solved. The following rules are considered here:

- $\quad$ the operating cost of the DER source is neglected;

- the use of the local ESS and V2G has to consider the degradation cost of the battery and the future cost of replacing the 'loaned energy' within the control horizon;

- $\quad$ the local ESS and V2G-ESS may have comparable degradation cost;

- the EMC uses the alternative sources (PV, V2G, S-ESS) only if economically convenient. Thus, the maximum operative cost of the system is obtained when the full energy provision is provided by the grid;

- $\quad$ subsequent layers may not modify decisions made in earlier layers.

Under these rules the following priority levels have been defined and Table 1 reports the operating costs of each layer:

- $\quad$ priority 1 direct use of PV energy

- $\quad$ priority 2 indirect use of PV energy

- $\quad$ priority 3 indirect use of grid energy \& direct use of V2G energy

- $\quad$ priority 4 indirect use of V2G energy

- $\quad$ priority 5 direct use of grid energy

The operating modes are here classified as direct or indirect considering the intermediate use of the S-ESS as buffer between the other sources and the load.

As example, the PV energy has a null operating cost, thus it has the highest priority level. The ML-DEMC will first allocate this energy if the load request coincides with to the PV production (priority 1). The subsequent layer will verify if the PV overproduction can be recovered using the buffering function of the S-ESS (indirect use of PV energy, priority 2). Thus, it will calculate the S-ESS degradation cost related to the charge-discharge process and will compare it with the cost of the other available sources to verify the affordability.

Other operating modes (e.g., energy sell to grid, ancillary services retribution, ...) and resulting benefits can be further implemented using the proposed rule-based approach. Nevertheless, the scope of this paper is not to demonstrate the benefits of grid-connected DES systems or V2G operation, instead this paper proposes a methodology to solve the energy management problem of the MS-EVCS with the purpose of a real-time implementation.

Table 1. MS-EVCS priority levels: lower number represents high priority level.

\begin{tabular}{ccccc}
\hline Source & \multicolumn{2}{c}{ Direct Supply } & \multicolumn{2}{c}{ Indirect Supply } \\
\hline & $C_{\pi}[h]$ & Priority & $C_{\pi}[h]$ & Priority \\
\hline grid & $c_{\mathrm{g}}[h]$ & 5 & $c_{\mathrm{deg}}[h]+c_{\mathrm{g}}\left[h^{\prime}\right]$ & 3 \\
PV & 0 & 1 & $c_{\mathrm{deg}}\left[h^{\prime}\right]$ & 2 \\
V2G & $c_{\mathrm{V} 2 \mathrm{G}}[h]+c_{\mathrm{r}}\left[h^{\prime}\right]$ & 3 & $c_{\mathrm{deg}}[h]+c_{\mathrm{V} 2 \mathrm{G}}\left[h^{\prime}\right]+c_{\mathrm{r}}\left[h^{\prime}\right]$ & 4 \\
\hline
\end{tabular}

\subsection{Deterministic Analysis}

For every stochastic scenario, the ML-DEMC solves the energy management problem of the MS-EVCS, evaluating the deterministic optimal solution of several cascaded subproblems. Afterworlds, a Monte Carlo methodology is applied to identify the statistic solution to the energy management, as described in Section 3.3. 
The priority levels are sorted considering the possibility of supplying the load with more convenient energy sources. Every priority level constitutes an optimization problem over the control horizon based on Equation (12) in which the sources under test are defined by the priority level, while the other sources are ignored. The load energy allocated in the previous level is deduced from the total energy to allocate $P_{\mathrm{EV}}^{\prime}$ and the energy allocated during high priority levels cannot be modified in subsequent levels. Thus, an optimal control policy $\pi^{\mathrm{pr}}$ is calculated for each priority level, however the $\pi^{\text {opt }}$ is updated only if the operating cost of the new solution is lower than the one of the previous level. Finally, in case priority 2 or 3 are not convenient, the ML-DEMC is rerouted to priority 5, avoiding combinations with higher cost. As an example, if it is not convenient to use the indirect PV energy (where the primary energy source has null cost) during the whole control horizon, it obviously will not be convenient to use the indirect grid energy, where the battery degradation cost is added to the grid energy cost.

Figure 2a shows the flow chart of the ML-DEMC algorithm, while Figure $2 b$ depicts a generic scenario of cost and power rates of the MS-EVCS that will be used for the following explanation.

\subsubsection{Priority 1}

The use of the PV energy to directly supply the EV load certainly allows for a reduction in the operating cost, and, thus, it has the highest priority. A $C_{\pi}^{\text {opt }}$ is defined and the hourly power of the load $P_{\mathrm{EV}}^{\prime}$ is updated for the next layer, subtracting the allocated $P_{\mathrm{PV}}^{\prime}$ with the related efficiency losses. The energy allocated by priority $1\left(P_{\mathrm{EV}, \mathrm{pr} 1}\right)$ and the energy to allocate during the following priority levels $\left(P_{\mathrm{EV}, \text { pr2-5 }}\right)$ are depicted in Figure $2 \mathrm{~b}$.

\subsubsection{Priority 2}

The surplus of PV energy production ( $P_{\mathrm{PV}, \mathrm{pr} 2}$ in Figure 2b) could lead to a minimization of $C_{\pi}$ if part/all of the energy is stored in the S-ESS and used when the electricity price $\left(c_{\mathrm{g}}[h]\right)$ is higher than the related degradation $\operatorname{cost} c_{\operatorname{deg}}[h]$. The ML-DEMC initially identifies the time intervals in which a surplus of PV energy is present (e.g., $\left.P_{\mathrm{PV}}[h]>P_{\mathrm{EV}}[h]\right),\left[h_{\mathrm{s}}^{\text {in }}, h_{\mathrm{s}}^{\text {lout }}\right]$ and $\left[h_{\mathrm{s}}^{2 \text { in }}, h_{\mathrm{s}}^{2 \text { out }}\right]$. For every single interval, the algorithm evaluates if the S-ESS has the capabilities of storing the PV energy surplus (e.g., $S o C\left[h_{\mathrm{s}}^{1 \text { in }}\right]$, $S o C\left[h_{\mathrm{s}}^{2 i n}\right]<100 \%$ ). Thus, it evaluates the amount of energy (taking into account the efficiency of the power conversion units) that can be used to minimize the operating cost in the optimization intervals $\left[1, h_{\mathrm{s}}^{1 \text { in }}[\cup] h_{\mathrm{s}}^{1 \text { out }}, h_{\mathrm{s}}^{2 \text { in }}[\cup] h_{\mathrm{s}}^{2 \text { out }}, N\right]$. In fact, the ML-DEMC tries to charge-discharge the S-ESS several times during the control horizon to minimize the waste of PV energy.

For each optimization interval, the ML-DEMC proceeds with the following optimization procedure:

1. a cluster of tuples $\left(h^{\mathrm{i}}, c_{\mathrm{g}, \mathrm{i} u}^{\mathrm{i}}\right)$ is defined with $i$ representing the time stamp of the interval. A cluster $\mathbf{M}$ is determined by sorting the tuples in decreasing order by electricity price:

$$
\mathbf{M}=\left\{\left(h^{\mathrm{hi}}, c_{\mathrm{g}, \mathrm{pu}}^{\mathrm{hi}}\right), \ldots,\left(h^{\mathrm{lo}}, c_{\mathrm{g}, \mathrm{pu}}^{\mathrm{lo}}\right)\right\}
$$

2. the optimization function allocates the indirect PV energy (stored in the S-ESS) starting from the tuples with the highest price, until it runs out of energy;

3. a new $C \pi$ can be calculated considering the electricity price reduction and the inclusion of $c_{\mathrm{deg}}$ for each of the tuples;

4. the ML-DEMC iteratively runs across the possible combinations discarding step-by-step the tuples with lower $c_{\mathrm{g}, \mathrm{pu}}$ until finding a $C_{\pi}^{\mathrm{pr} 2}$ lower than $C_{\pi}^{\mathrm{opt}}$.

This mechanism takes advantage of the local monotonicity feature of the problem [23] and is then applied to all the priority levels. 


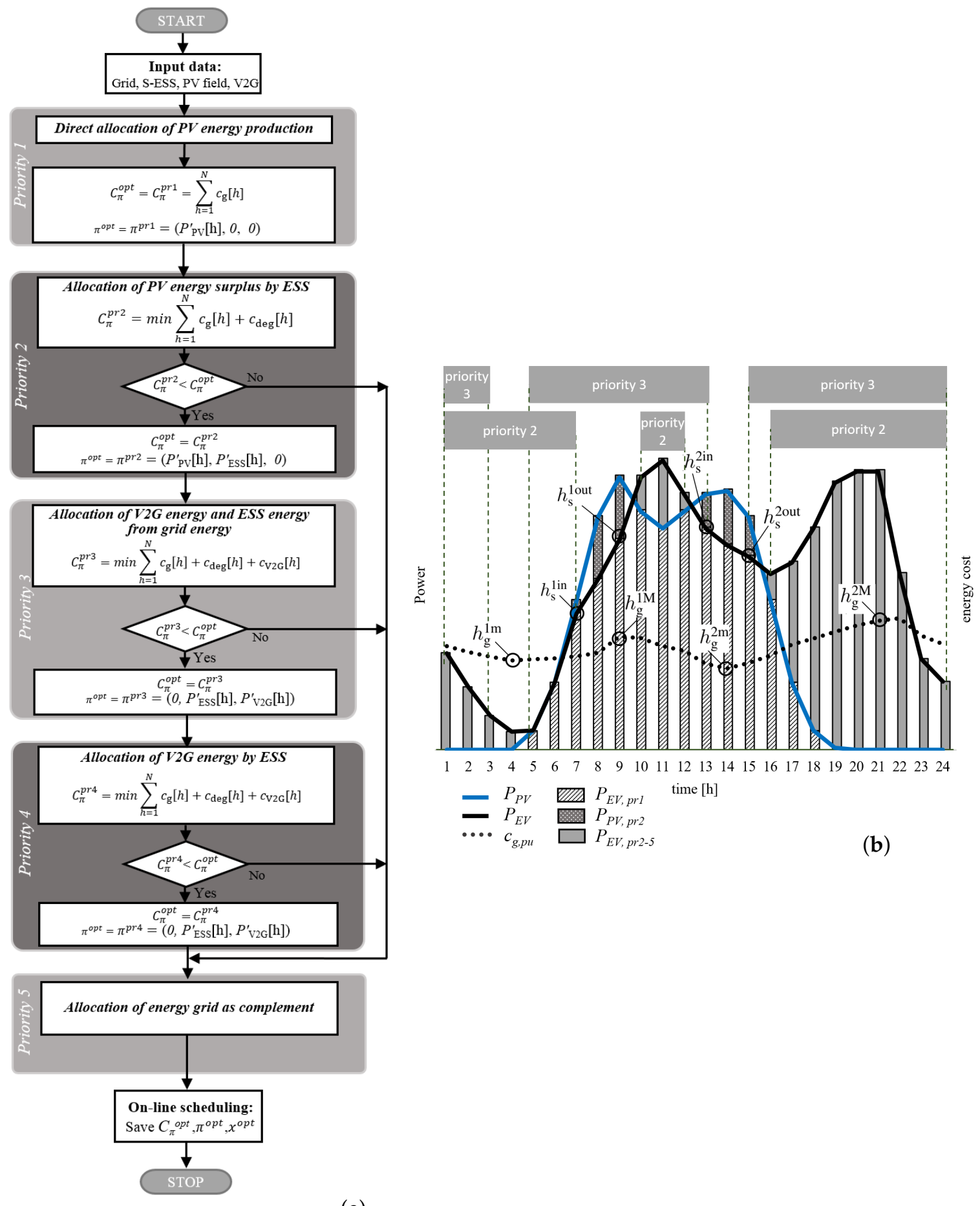

(a)

Figure 2. (a) Flow chart of the ML-DEMC algorithm. (b) Generic scenario of the MS-EVCS data.

\subsubsection{Priority 3}

Priority 3 is based on the indirect use of the grid (time-shift) and the direct use of the V2G energy. In the time-shift operating mode the ML-DEMC evaluates the possibility of purchasing grid electricity at a convenient price at the $h^{\prime}$-th control interval, storing it in the S-ESS, and using the energy in the optimal time interval $h$. The related cost of this operating mode is $c_{\mathrm{g}}\left[h^{\prime}\right]+c_{\operatorname{deg}}[h]$. If the V2G EMC has any energy availability at the interval $h$, the ML-DEMC can evaluate the convenience of using its energy to directly supply the load. The cost of this operating mode is $c_{\mathrm{V} 2 \mathrm{G}}[h]+c_{\mathrm{r}}\left[h^{\prime}\right]$, where 
$c_{\mathrm{r}}\left[h^{\prime}\right]$ represents the additional cost related to the replacement of the V2G battery energy during the interval $h^{\prime}$, within the vehicle owner request. It is clear that these two operating modes cannot be treated separately, because they may have similar cost magnitude, depending on the relation between the degradation cost of V2G-ESS and S-ESS. Several optimization intervals have to be investigated for solving this optimization layer considering relative and absolute minimum $\left(h_{\mathrm{g}}^{1 \mathrm{~m}}\right.$ and $\left.h_{\mathrm{g}}^{2 \mathrm{~m}}\right)$ and maximum $\left(h_{\mathrm{g}}^{1 \mathrm{M}}\right.$ and $\left.h_{\mathrm{g}}^{2 \mathrm{M}}\right)$ cost $c_{\mathrm{g}, \mathrm{pu}}$, as shown in Figure $2 \mathrm{~b}$. In detail, the algorithm evaluates the possibility of purchasing some energy in $h_{\mathrm{g}}^{1 \mathrm{~m}}$ and $h_{\mathrm{g}}^{2 \mathrm{~m}}$ (from the grid or from the V2G) using the optimization procedure previously defined.

Thus, all the energy available from V2G and time-shift is initially allocated and progressively decreased considering all the possible combinations of power sharing. The combinations are separately analyzed by calling the optimization function for the evaluation of the optimal $C_{\pi}^{\text {pr3 }}$ several times. The cost of V2G energy and the V2G charge energy are dynamically provided by the V2G EMC, as described in Section 2.2. If $C_{\pi}^{\mathrm{pr} 3}$ is lower than the current $C_{\pi}^{\text {opt }}$, the optimal policy is updated.

\subsubsection{Priority 4}

The energy residue of the V2G-ESSs can be stored in the S-ESS to support the MS-EVCS when the electricity cost is extremely high, if that allows minimizing $C_{\pi}$. In this case the degradation cost, the power losses of the conversion system, and the ESS efficiency have to be considered for both S-ESS and V2G-ESSs. The algorithm evaluates the amount of V2G surplus that can be stored in the S-ESS without overcharging it. The optimization function is called across the whole control horizon. The cost of the VG2 is provided by V2G EMC. A new $C_{\pi}^{\mathrm{pr} 4}$ is obtained and compared with the actual $C_{\pi}^{\mathrm{opt}}$. Thus, if a lower cost is reached the optimal schedule of the available sources is obtained.

\subsubsection{Priority 5}

The residual energy load is, finally, supplied by the grid (priority 5), since at this point all the possible operating modes have been investigated.

\subsection{Stochastic Analysis}

The day-ahead schedule is used in this work for the definition of the initial SoC[1] of the S-ESS. In detail, the initial $S_{o C}[1]$ of the S-ESS determines the quantity of energy that the charging station can accumulate and use during the time horizon, since a null energy balance has to be guaranteed during the control horizon. For example, starting with a partially charged S-ESS, the optimal solution could foresee a charging event early in the morning, when the grid energy cost is lower and/or there is an overproduction of PV energy. The S-ESS may be discharged later on in the day when grid energy must be purchased at higher cost. However, the use of S-ESS is subject to the degradation $\operatorname{cost} c_{\text {deg }}$ that exponentially increases when the S-ESS operates at low SoC. Thus, the definition of SoC[1] represents a crucial point for the minimization of the operating cost.

A Monte Carlo approach is used for the definition of the stochastic day-ahead schedule of the multi source station. Several scenarios can be defined considering that the parameters are randomly selected by means of PdFs of DES production, electricity price, EV load, and V2G availability based on historical data and prediction of the EV owner behavior [24]. For each scenario a deterministic problem is solved and a statistic control policy is predicted based on the Monte Carlo method. In order to minimize $C_{\pi}$, the proposed algorithm iterates the solution of the optimization problem for each scenario considering different values of initial $S o C[1]$, from minimum to maximum admissible value for S-ESS technology. At the end of the statistic analysis, the minimum $C_{\pi}$ will identify the predicted SoC[1]. As matter of fact, the ML-DEMC will optimize the $S o C$ trend in such a way that the S-ESS has high $S o C$ values before the discharge process. The optimal $S o C[1]$ will highly influenced by the seasonal DER availability and grid energy cost variation. For example, during the month of January the optimal SoC[1] values will be higher than the one in July, since there is less probability of PV energy surplus. Thus, the algorithm will identify starting with at high $\operatorname{SoC}[1]$ as more convenient, 
corresponding to a lower degradation cost. More details of the SoC trend are shown in the numerical result section.

\section{Numerical Results}

In order to analyze the performances of the proposed energy management control, a MS-EVCS, based on the structure of Figure $1 \mathrm{a}$, has been modeled in the Matlab ${ }^{\circledR}$ programming language. The time horizon has been fixed to one day with a sampling interval of $1 \mathrm{~h}(N=24)$. However, shorter time resolutions are possible for a real-time implementation. The MS-EVCS is composed by a grid connection of $110 \mathrm{~kW}$, a $120 \mathrm{kWp}$ PV field, a lead-acid S-ESS having a capacity of $275 \mathrm{kWh}$, and a EV maximum load of $110 \mathrm{~kW}$. The SoC variation of the S-ESS has been limited within the range $50-100 \%$, due to the technology limitation of lead acid batteries. The V2G fleet is composed by $N_{\mathrm{V} 2 \mathrm{G}}=3$, with $24 \mathrm{kWh}$ - and $32 \mathrm{kWh}-\mathrm{ESS}$. The SoC of the vehicles has been defined by a random process within the range 50-100\%, due to the owner requirement of minimum charge available at any moment. The capital cost of the ESS is reported in Table 2, considering two different scenarios for the degradation cost impact. The $L(D o D)$ characteristics for lead acid and lithium-ion batteries are reported in Figure 3. In this paper, a linear function has been adopted for the lead acid technology, whereas the logarithmic function for the lithium-ion one has been approximated with a piecewise linear function. In this paper, a linear function has been adopted for the lead acid technology, whereas the logarithmic function for the lithium-ion one has been approximated with a piecewise linear function. The efficiency of the single energy conversion unit is function of the processed power with a peak efficiency equal to $95 \%[25,26]$, in line with the state of the art. The ESS round trip efficiency (discharge and charge using a CC-CV protocol) is considered equal to $90 \%$ for Li-ion technology and $84 \%$ for Lead-acid [27]. Gaussian PdFs for each hour of the day have been defined for the PV production, the load demand, and the presence of EVs in V2G mode to forecast the operating condition of the MS-EVCS. PV production and electricity price have been modeled by means available historical data. A typical charge profile of EVs in the metropolitan area has been considered [24].

Table 2. ESS capital cost.

\begin{tabular}{cccc}
\hline ESS & Technology & Case 1 & Case 2 \\
\hline S-ESS & lead acid & $0.10 € / \mathrm{Wh}$ & $0.07 € / \mathrm{Wh}$ \\
V2G-ESS & lithium ion & $0.30 € / \mathrm{Wh}$ & $0.20 € / \mathrm{Wh}$ \\
\hline
\end{tabular}

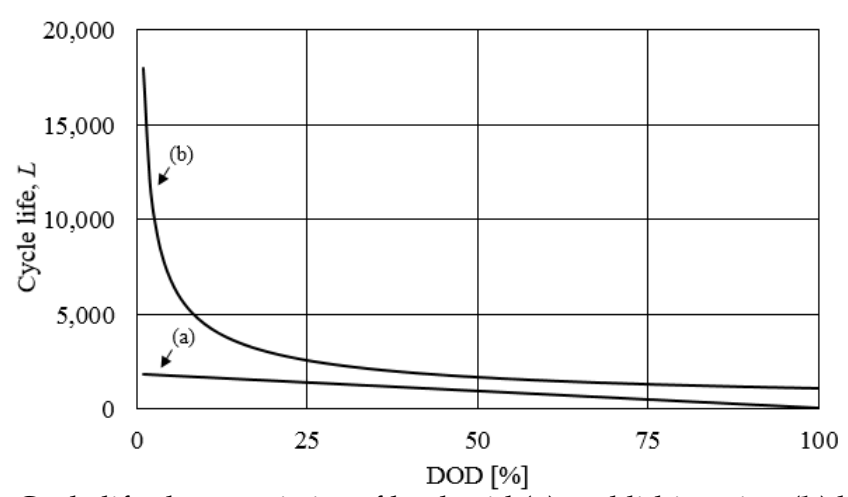

Figure 3. Cycle life characteristics of lead acid (a) and lithium-ion (b) batteries.

Figure 4 represents the daily optimal control policy $\pi^{\mathrm{opt}}$ of the MS-EVCS considering the reported constraint of $P_{\mathrm{EV}}, P_{\mathrm{PV}}^{\max }$, and the unit electricity $\operatorname{cost} c_{\mathrm{g}, \mathrm{pu}}$ for a typical day in winter, spring, summer, and autumn when case 2 is applied. The SoC[1] has been evaluated with the analysis reported in Section 4.2. The ML-DEMC optimizes the use of the $P_{\mathrm{PV}}$ directly supplying the load or charging the S-ESS (priority 1 and 2). The stored energy during priority 2 is then used when the grid energy has the highest cost 
(around $h=20$ ). Priority 3 is present only during day of December and results in storing the grid energy at $h=5$ to charge the S-ESS to be used at $h=18$ when the grid energy cost is maximum (time-shift operation). As matter of fact, priority 3 is not used during the other months, since there is already a surplus of PV energy that the system is not cable of allocating. Moreover, the ML-DEMC decides to use the V2G energy in several afternoon events due to the source availability, the low cost related to the $S o C$ of the EVs, and the high cost of the grid energy. The effectiveness of the proposed ML-DEMC is verified in Figure 5 for the month of December, highlighting the cost reduction of every priority level in comparison with the grid electricity price $C_{\pi}^{\text {grid }}[h]=c_{\mathrm{g}, \mathrm{pu}}[h] P_{\mathrm{EV}}[h]=77.86 €$. The priority 1 allows achieving $C_{\pi}^{\mathrm{pr} 1}[h]=53.59 €$, priority $2 C_{\pi}^{\mathrm{pr} 2}[h]=52.3 €$ and priority $3 C_{\pi}^{\mathrm{pr} 3}[h]=52.05 €$, while priority 4 is not used in this case.
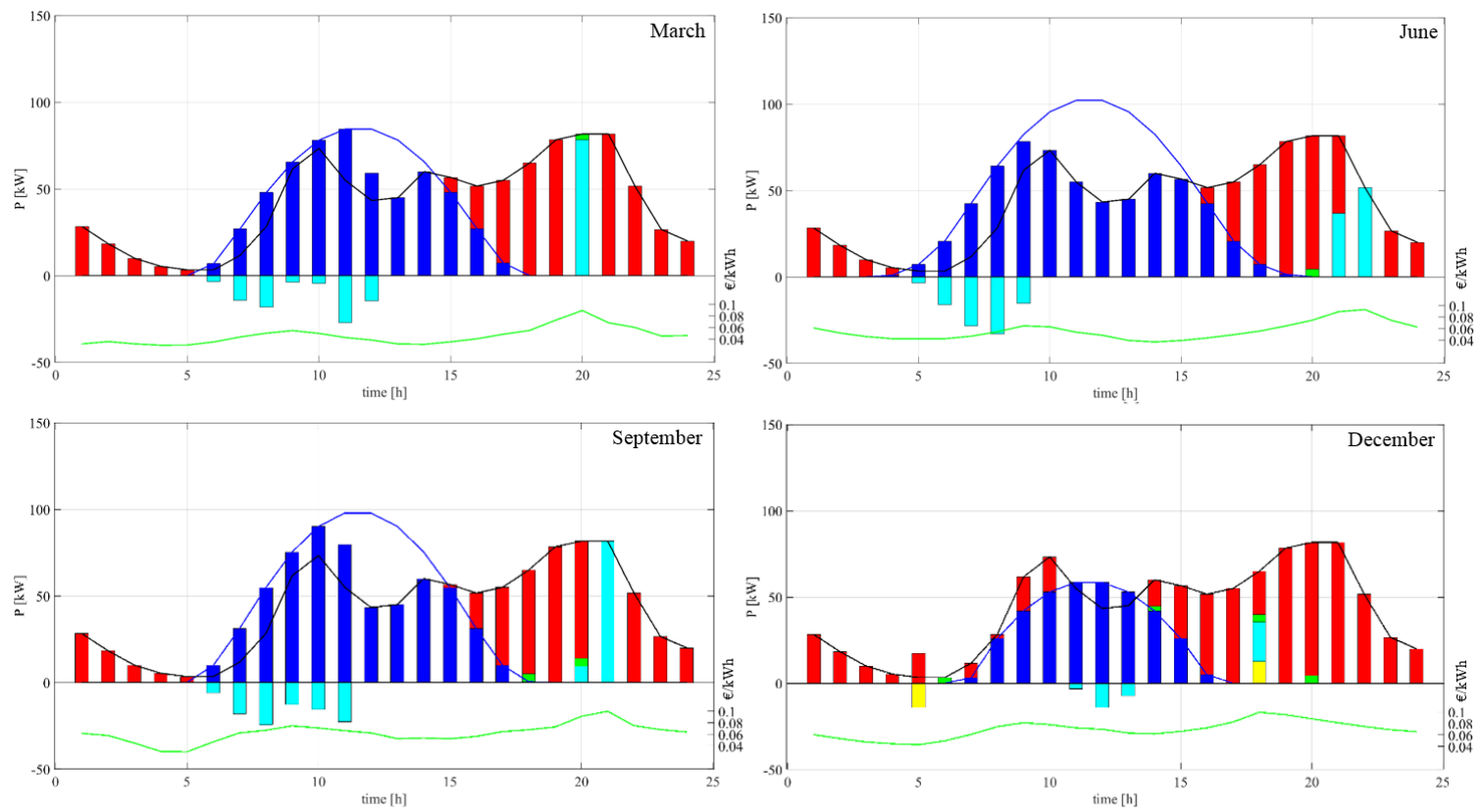

$P_{\mathrm{g}} \quad \square P_{\mathrm{PV}} \quad \square P_{\mathrm{ESS}^{p r 2}}^{p r} \square P_{\mathrm{ESS}^{p r 3}}^{p P_{\mathrm{V} 2 \mathrm{G}}} \quad-P_{\mathrm{G} 2 \mathrm{~V}} \quad-P_{\mathrm{PV}}^{\max }-c_{\mathrm{g}, \mathrm{pu}}$

Figure 4. Power schedule for a day of December considering the proper $S o C[1]$.
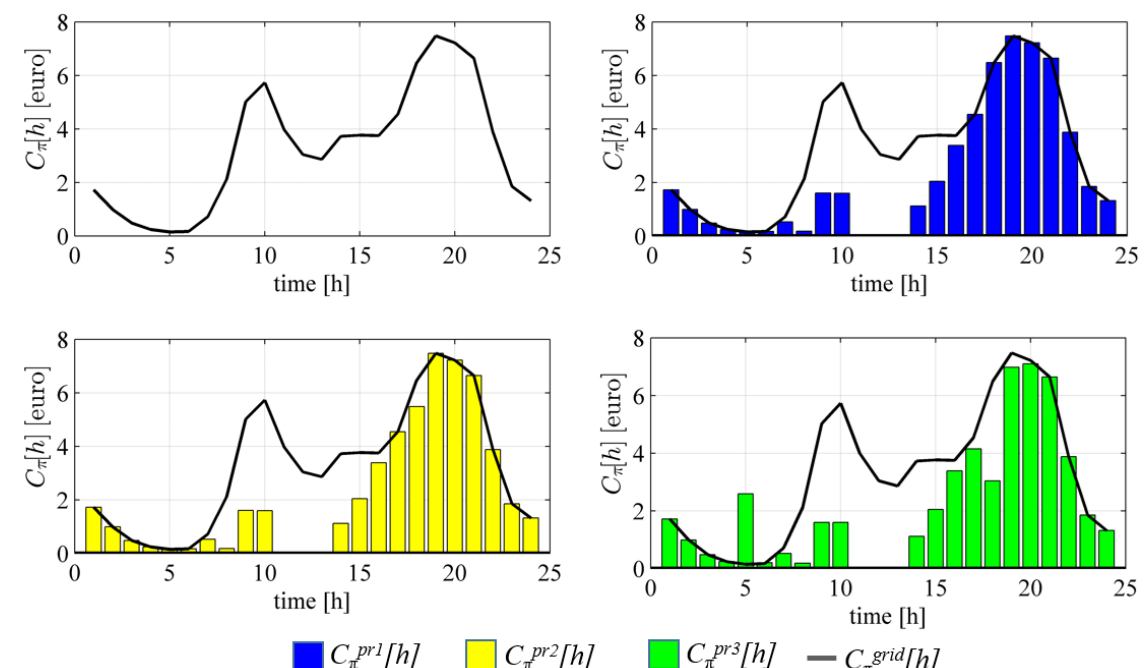

Figure 5. December: optimal operating cost for different priority levels. 


\subsection{Comparison with Dynamic Programming Solution}

A DP method is used as benchmark to evaluate the potential of the ML-DEMC and the optimality of the proposed control strategy. The optimization problem, reported in Section 2.3, can be tackled using the Matlab-based DP function proposed in [17]. A convenient way to analyze the optimization algorithm results for MS-EVCS is the introduction of usage factors of the sources. $P_{\mathrm{i}, \mathrm{pu}}$ represents the percentage of total utilization of the i-th source considering the power contribute used to supply the load with comparison to the load demand:

$$
P_{\mathrm{i}, \mathrm{pu}}=\frac{\sum_{h=1}^{N} P_{\mathrm{i}}[h]}{\sum_{h=1}^{N} P_{\mathrm{EV}}[h]}
$$

The index is calculated considering the power balance at the DC-link, taking into account the conversion efficiency. Whereas the usage factor of $\mathrm{g}$, $\mathrm{PV}$, and V2G represent the direct and indirect power contribute of grid, $\mathrm{PV}$, and $\mathrm{V} 2 \mathrm{G}$ to the load supply. Thus,

$$
P_{\mathrm{g}, \mathrm{pu}}+P_{\mathrm{PV}, \mathrm{pu}}+P_{\mathrm{V} 2 \mathrm{G}, \mathrm{pu}}=1
$$

Since the energy balance of the S-ESS over the control horizon is defined to be null, the index $P_{\mathrm{ESS}, \mathrm{pu}}$ is calculated considering the only discharge contribute $P_{\mathrm{ESS}, \mathrm{d}}[h]$ :

$$
P_{\mathrm{ESS}, \mathrm{pu}}=\frac{\sum_{h=1}^{N} P_{\mathrm{ESS}, \mathrm{d}}[h]}{\sum_{h=1}^{N} P_{\mathrm{EV}}[h]}
$$

Thus, $P_{\mathrm{ESS}, \mathrm{pu}}$ stands for the indirect power contribution of the grid, PV, and V2G to the load supply. Table 3 includes the values of proposed indexes and optimal $C_{\pi}$ for different months and ESS capital costs. It can be observed that the proposed algorithm carries out the same utilization factors and operating cost of the DP solution. Check of the hourly sources' power has been performed. Furthermore, $C_{\pi}$ is affected by the capital cost of the ESS, especially during the summer months when the PV surplus is higher. As is well known, the computational effort of DP algorithm increases exponentially with the number of states, inputs, time steps, and required accuracy. The number of inputs has been defined as the dimension of the control policy $\pi$ in which the $P_{\mathrm{V} 2 \mathrm{G}}$ power reference is defined for every vehicles. In the same manner, the number of states is equal to the number of ESSs.

\begin{tabular}{|c|c|c|c|c|c|c|c|c|c|c|c|}
\hline \multirow{2}{*}{ Month } & \multirow{2}{*}{ Case } & \multicolumn{2}{|c|}{$C_{\pi}[€]$} & \multicolumn{2}{|c|}{$P_{\mathrm{g}, \mathrm{pu}}[\%]$} & \multicolumn{2}{|c|}{$P_{\mathrm{PV}, \mathrm{pu}}[\%]$} & \multicolumn{2}{|c|}{$P_{\mathrm{V} 2 \mathrm{G}, \mathrm{pu}}[\%]$} & \multicolumn{2}{|c|}{$P_{\text {ESS,pu }}[\%]$} \\
\hline & & DP & ML-DEMC & DP & ML-DEMC & DP & ML-DEMC & DP & ML-DEMC & DP & ML-DEMC \\
\hline \multirow{2}{*}{ March } & 1 & 32.45 & 32.29 & 51.19 & 51.51 & 49.34 & 48.34 & 0.16 & 0.15 & 5.90 & 5.96 \\
\hline & 2 & 30.74 & 30.58 & 49.92 & 50.13 & 49.13 & 49.52 & 0.42 & 0.35 & 8.75 & 8.40 \\
\hline \multirow{2}{*}{ June } & 1 & 33.76 & 34.00 & 46.26 & 46.99 & 54.14 & 53.61 & 0.00 & 0.00 & 6.07 & 5.96 \\
\hline & 2 & 31.98 & 32.30 & 44.13 & 43.99 & 55.09 & 55.52 & 0.46 & 0.49 & 9.92 & 9.48 \\
\hline \multirow{2}{*}{ September } & 1 & 39.22 & 38.79 & 49.19 & 49.46 & 50.12 & 50.33 & 0.23 & 0.21 & 7.12 & 7.04 \\
\hline & 2 & 36.92 & 36.76 & 47.71 & 47.31 & 51.45 & 51.71 & 0.94 & 0.99 & 9.52 & 9.75 \\
\hline \multirow{2}{*}{ December } & 1 & 52.83 & 52.72 & 64.75 & 65.18 & 34.56 & 34.27 & 0.60 & 0.55 & 2.36 & 2.42 \\
\hline & 2 & 51,72 & 52.05 & 64.27 & 63.74 & 34.48 & 34.72 & 1.46 & 1.54 & 3.62 & 3.79 \\
\hline
\end{tabular}
The proposed ML-DEMC is an order of magnitude faster than standard DP.

Table 3. Comparison DP/ML-DEMC.

\subsection{Numerical Results of the Stochastic Analysis}

The main results of the stochastic analysis are reported in Figure 6. The developed model and control algorithm have been used to solve several optimization problems using a Monte Carlo approach where PdFs of DES production $(\mu=17 \%)$, electricy price $(\mu=10 \%)$, EV load $(\mu=10 \%)$, and V2G availability ( $\mu=10 \%$ ) have been considered as input. A total of 1000 scenarios have been considered. For every scenario the algorithm solves the problem considering different values of $S o C[1]$ 
(within the technologies limits). In detail, the ML-DEMC statistically determines for each analyzed month which is the value of $S_{0} C[1]$ that allows minimizing the $C_{\pi}$. As a result of the numerical analysis, Figures 4 and 7 show how for achieving the lowest $c_{\text {deg }}$ the ML-DEMC optimizes the SoC[1] with the aim to obtain a fully-charged S-ESS before the first discharge process. Moreover, the S-ESS finds a more intensive use in the summer months with respect to the winter ones especially when a low degradation cost of the ESS is considered (case 2).
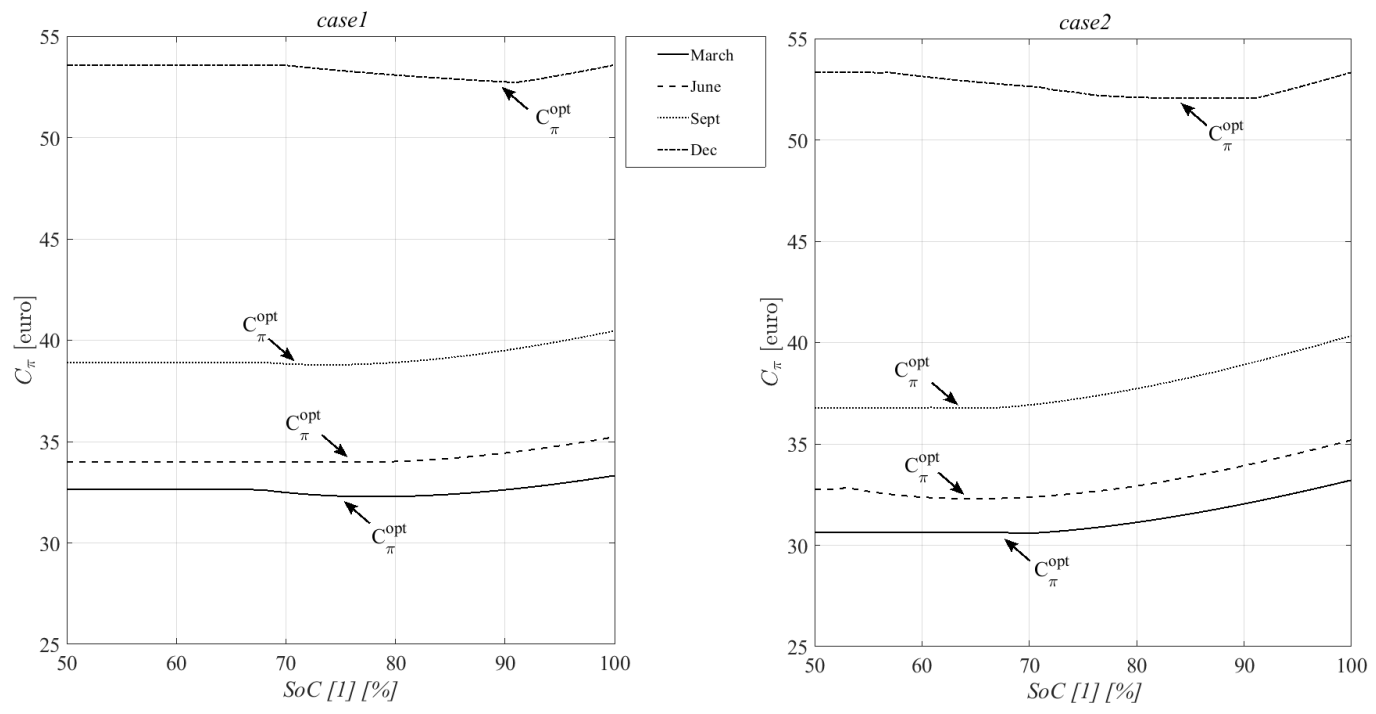

Figure 6. Stochastic analysis for the $S o C[1]$ evaluation.
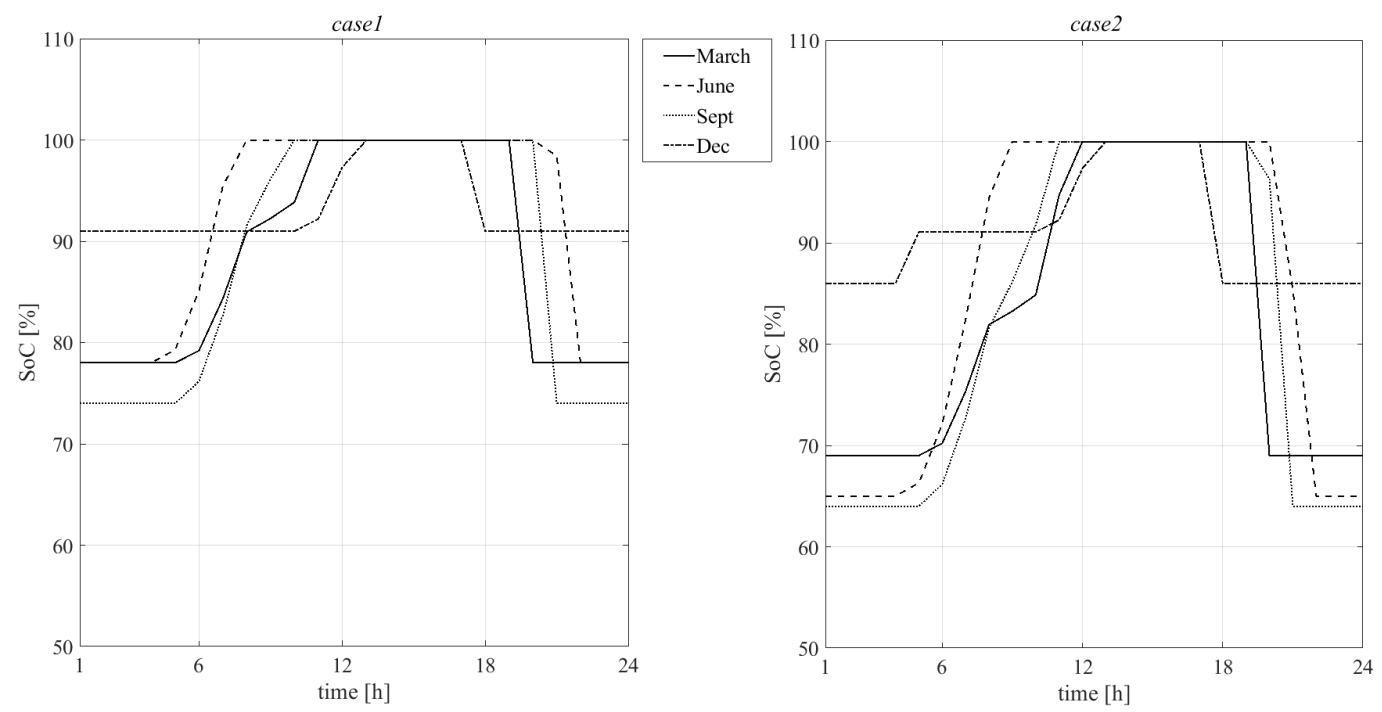

Figure 7. State of charge of the S-ESS for the operating points in Figure 4 (case2) and Table 3.

\subsection{Real-Time Analysis}

With respect to Figure 4, a perturbation of $P_{\mathrm{EV}}$ is reported in Figure 8. In detail, due to the load addition at $h=10$, the ML-DEMC decides to use the S-ESS stored during the time-shift $(h=5)$, since the prediction algorithm has estimated a load decreases at $h=12-13$. Thus, the PV surplus during this interval is used to charge the S-ESS to be used at $h=18$. A new optimal policy is obtained for the control horizon $h=(10,24)$. 


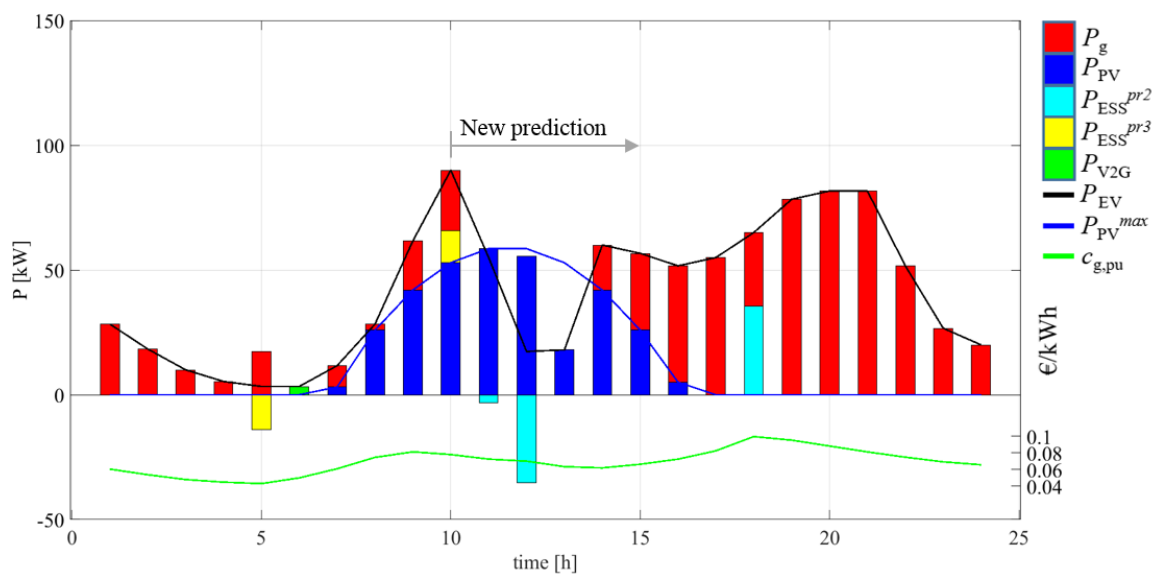

Figure 8. Real-time operation for a day of December considering a load perturbation.

\section{Conclusions}

This paper presents a new approach for real-time control of MS-EVCS that achieves the minimum operating cost when the degradation cost of both S-ESS and V2G-ESS is considered. The optimization algorithm solution has been shown to be accurate and it requires less computational effort when compared to standard solution methods, enabling the real-time implementation. This goal is achieved by defining proper priority levels among the system sources (grid, V2G, S-ESS, PV) and solving the optimal control problem layer-by-layer. An external V2G EMC is used to define the best operating condition for the V2G fleet; the V2G management takes advantage of pre-calculated look-up-table based the vehicle parameters. A unique contribution of this paper is the study of the SOC initial condition for the S-ESS considering seasonal and economic constraints. In detail, a day-ahead statistic analysis calculates the estimated initial state of charge of the S-ESS that will guarantee the operating cost minimization.

Author Contributions: Formal analysis, U.A., M.D. and M.D.M.; Methodology, U.A., M.D., M.D.M. and G.T.; Supervision, C.A. and G.T.

Funding: This research was in part funded by the Italian National Agency fr New Technolgies, Energy and Sustainable Economic Development (ENEA), grant number RdS/PAR2014/104.

Conflicts of Interest: The authors declare no conflict of interest.

\section{References}

1. Habib, S.; Khan, M.M.; Abbas, F.; Sang, L.; Shahid, M.U.; Tang, H. A Comprehensive Study of Implemented International Standards, Technical Challenges, Impacts and Prospects for Electric Vehicles. IEEE Access 2018, 6, 13866-13890. [CrossRef]

2. Veldman, E.; Verzijlbergh, R.A. Distribution grid impacts of smart electric vehicle charging from different perspectives. IEEE Trans. Smart Grid 2015, 6, 333-342. [CrossRef]

3. Clement-Nyns, K.; Haesen, E.; Driesen, J. The Impact of Charging Plug-In Hybrid Electric Vehicles on a Residential Distribution Grid. IEEE Trans. Power Syst. 2010, 25, 371-380. [CrossRef]

4. Dragicevic, T.; Lu, X.; Vasquez, J.C.; Guerrero, J.M. DC Microgrids-Part II: A Review of Power Architectures, Applications, and Standardization Issues. IEEE Trans. Power Electron. 2016, 31, 3528-3549. [CrossRef]

5. Badawy, M.O.; Sozer, Y. Power Flow Management of a Grid Tied PV-Battery System for Electric Vehicles Charging. IEEE Trans. Ind. Appl. 2017, 53, 1347-1357. [CrossRef]

6. Abronzini, U.; Attaianese, C.; D’Arpino, M.; Monaco, M.D.; Genovese, A.; Pede, G.; Tomasso, G. Optimal energy control for smart charging infrastructures with ESS and REG. In Proceedings of the 2016 ESARS-ITEC Conference, Toulouse, France, 2-4 November 2016; pp. 1-6. [CrossRef] 
7. Damiano, A.; Gatto, G.; Marongiu, I.; Porru, M.; Serpi, A. Vehicle-to-grid technology: State-of-the-art and future scenarios. J. Energy Power Eng. 2014, 8, 152-165.

8. Deng, R.; Yang, Z.; Chow, M.Y.; Chen, J. A Survey on Demand Response in Smart Grids: Mathematical Models and Approaches. IEEE Trans. Ind. Inform. 2015, 11, 570-582. [CrossRef]

9. Chaudhari, K.; Ukil, A.; Kumar, K.N.; Manandhar, U.; Kollimalla, S.K. Hybrid optimization for economic deployment of ESS in PV-integrated EV charging stations. IEEE Trans. Ind. Inform. 2018, 14, 106-116. [CrossRef]

10. Abronzini, U.; Attaianese, C.; D’Arpino, M.; Monaco, M.D.; Genovese, A.; Pede, G.; Tomasso, G. Multi-source power converter system for EV charging station with integrated ESS. In Proceedings of the 2015 IEEE 1st International Forum on Research and Technologies for Society and Industry Leveraging a Better Tomorrow (RTSI), Torino, Italy, 16-18 September 2015; pp. 427-432. [CrossRef]

11. Zhou, C.; Qian, K.; Allan, M.; Zhou, W. Modeling of the cost of EV battery wear due to V2G application in power systems. IEEE Trans. Energy Convers. 2011, 26, 1041-1050. [CrossRef]

12. Ortega-Vazquez, M.A. Optimal scheduling of electric vehicle charging and vehicle-to-grid services at household level including battery degradation and price uncertainty. IET Gener. Transm. Distrib. 2014, 8, 1007-1016. [CrossRef]

13. Farzin, H.; Fotuhi-Firuzabad, M.; Moeini-Aghtaie, M. A Practical Scheme to Involve Degradation Cost of Lithium-Ion Batteries in Vehicle-to-Grid Applications. IEEE Trans. Sustain. Energy 2016, 7, 1730-1738. [CrossRef]

14. Ahmadian, A.; Sedghi, M.; Mohammadi-ivatloo, B.; Elkamel, A.; Golkar, M.A.; Fowler, M. Cost-Benefit Analysis of V2G Implementation in Distribution Networks Considering PEVs Battery Degradation. IEEE Trans. Sustain. Energy 2018, 9, 961-970. [CrossRef]

15. Han, S.; Aki, H.; Han, S. A practical battery wear model for electric vehicle charging applications. In Proceedings of the 2013 IEEE Power Energy Society General Meeting, Vancouver, BC, Canada, 21-25 July 2013; pp. 1-5.

16. Biral, F.; Bertolazzi, E.; Bosetti, P. Notes on numerical methods for solving optimal control problems. IEEE J. Ind. Appl. 2016, 5, 154-166. [CrossRef]

17. Sundstrom, O.; Guzzella, L. A generic dynamic programming Matlab function. In Proceedings of the 2009 IEEE Control Applications, (CCA) Intelligent Control, (ISIC), St. Petersburg, Russia, 8-10 July 2009; pp. 1625-1630. [CrossRef]

18. Attaianese, C.; Monaco, M.D.; Nardi, V.; Tomasso, G. Dual inverter for high efficiency PV systems. In Proceedings of the 2009 IEEE International Electric Machines and Drives Conference, Miami, FL, USA, 3-6 May 2009; pp. 818-825. [CrossRef]

19. Serpi, A.; Porru, M.; Damiano, A. An Optimal Power and Energy Management by Hybrid Energy Storage Systems in Microgrids. Energies 2017, 10, 1909. [CrossRef]

20. Christophersen, J.P. Battery Test Manual For Electric Vehicles, rev. 3; Technical Report; Idaho National Lab. (INL): Idaho Falls, ID, USA, 2015.

21. Yilmaz, M.; Krein, P.T. Review of the impact of vehicle-to-grid technologies on distribution systems and utility interfaces. IEEE Trans. Power Electron. 2013, 28, 5673-5689. [CrossRef]

22. Shi, W.; Wong, V.W.S. Real-time vehicle-to-grid control algorithm under price uncertainty. In Proceedings of the 2011 IEEE International Conference on Smart Grid Communications (SmartGridComm), Brussels, Belgium, 17-20 October 2011; pp. 261-266. [CrossRef]

23. Stein, S.; Gerding, E.; Robu, V.; Jennings, N.R. A model-based online mechanism with pre-commitment and its application to electric vehicle charging. In Proceedings of the 11th International Conference on Autonomous Agents and Multiagent Systems-Volume 2, Taipei, Taiwan, 2-6 May 2012; International Foundation for Autonomous Agents and Multiagent Systems: Richland, SC, USA, 2012; pp. 669-676.

24. Celli, G.; Soma, G.G.; Pilo, F.; Lacu, F.; Mocci, S.; Natale, N. Aggregated electric vehicles load profiles with fast charging stations. In Proceedings of the 2014 Power Systems Computation Conference, Wroclaw, Poland, 18-22 August 2014; pp. 1-7. [CrossRef]

25. Attaianese, C.; D'Arpino, M.; Monaco, M.D.; Tomasso, G. Interleaving modulation inverters for high efficiency photovoltaic systems. In Proceedings of the 2014 IEEE PES General Meeting IConference Exposition, National Harbor, MD, USA, 27-31 July 2014; pp. 1-5. [CrossRef] 
26. SMA Solar Technology. Sunny Tripower. Available online: http:/ files.sma.de/dl/24336/STP25000TL-30DEN1742-V31web.pdf (accessed on 18 December 2018).

27. Valøen, L.O.; Shoesmith, M.I. The effect of PHEV and HEV duty cycles on battery and battery pack performance. In Proceedings of the PHEV 2007 Conference, Montréal, QC, Canada, 28-30 September 2007; pp. 4-5.

(C) 2019 by the authors. Licensee MDPI, Basel, Switzerland. This article is an open access article distributed under the terms and conditions of the Creative Commons Attribution (CC BY) license (http:// creativecommons.org/licenses/by/4.0/). 